\title{
Ildefonse Cathelinot, Réflexions sur le "Traité des Apparitions" de dom Calmet
}

\section{Simón Gallegos Gabilondo}

\section{(2) OpenEdition}

1 Journals

\section{Edizione digitale}

URL: http://journals.openedition.org/studifrancesi/7938

DOI: 10.4000/studifrancesi.7938

ISSN: 2421-5856

\section{Editore}

Rosenberg \& Sellier

\section{Edizione cartacea}

Data di pubblicazione: 1 juillet 2009

Paginazione: 401-402

ISSN: 0039-2944

\section{Notizia bibliografica digitale}

Simón Gallegos Gabilondo, «lldefonse Cathelinot, Réflexions sur le "Traité des Apparitions" de dom Calmet», Studi Francesi [Online], 158 (LIII | II) | 2009, online dal 30 novembre 2015, consultato il 09 janvier 2021. URL: http://journals.openedition.org/studifrancesi/7938 ; DOI: https://doi.org/10.4000/ studifrancesi.7938

Questo documento è stato generato automaticamente il 9 janvier 2021.

\section{(c)}

Studi Francesi è distribuita con Licenza Creative Commons Attribuzione - Non commerciale - Non opere derivate 4.0 Internazionale. 


\title{
Ildefonse Cathelinot, Réflexions sur le "Traité des Apparitions" de dom Calmet
}

\author{
Simón Gallegos Gabilondo
}

\section{NOTIZIA}

ILDEFONSE CATHELINOT, Réflexions sur le “Traité des Apparitions" de dom Calmet, texte établi, présenté et annoté par Gilles Banderier, Grenoble, Jerôme Milton, 2008, pp. 181.

1 Nel 1746 dom Augustin Calmet (1672-1757), esegeta biblico appartenente all'ordine dei Benedettini, pubblicò a Parigi le Dissertations sur les Apparitions des Anges, des démons et des esprits, et sur les revenants et vampires de Hongrie, de Bohème, de Moravie et de Silésie, un'opera che conobbe un notevole successo e che fu ristampata più volte con il titolo di Traité sur les Apparitions des esprits, et sur les vampires, ou les revenants de Hongrie, de Moravie, etc. (presso Simone Occhi, a Venezia, appariva nel 1756 l'edizione italiana). Il lavoro di dom Calmet ricevette però anche aspre critiche, tra le quali quella di Voltaire, che alla voce Vampires delle Questions sur l'Encyclopédie (1770), manifestò stupore e irritazione per il Traité, che, "ancora" nel Secolo dei Lumi, si occupava di simili oggetti di ricerca. La presa di posizione polemica del Patriarca di Ferney, espressa anche altrove nei suoi scritti, non rende tuttavia giustizia alla posizione di dom Calmet, che è più sfumata di quanto il philosophe non lasci supporre.

2 Il Traité si proponeva infatti principalmente di rendere più chiaro il confine tra verità $\mathrm{e}$ menzogna nelle opinioni comunemente espresse sull'esistenza di apparizioni di spiriti o altri eventi analoghi. L'atteggiamento del dotto benedettino appare diverso sia da chi crede ingenuamente a tutto, sia dall'uomo scettico. Il suo lavoro si colloca perciò nell'ambito della convivenza di fede e ragione, tradizionalmente difesa dal pensiero cristiano che cerca di evitare il conflitto tra teologia e filosofia. Nel Nuovo Testamento si trovano narrazioni di fatti che appaiono come eccezionali e sovrumani, che non possono perciò essere spiegati in sé stessi: questi non sono considerati da Dom Calmet come falsi, in quanto fondati sull'autorità delle Scritture. Allo stesso tempo l'autore 
ricorre però a spiegazioni di tipo razionale per gli accadimenti soprannaturali, e sostiene che gli uomini non comprendendo talvolta le ragioni di questi eventi attribuiscono le loro cause a Dio, unicamente perché non le conoscono. Il benedettino francese non crede a chi racconta di aver presenziato ad apparizioni di spiriti né ad una fede superstiziosa nell'esistenza nei vampiri, piuttosto diffusa nel xvIII secolo. Il suo scetticismo investe, per così dire, tutte queste credenze popolari in quanto sprovviste di fondamento, con la sola eccezione delle apparizioni riportate dalla Bibbia, e poche altre.

Dom Ildefonse Cathelinot (1671-1756), anch'egli benedettino, lasciò la maggior parte dei suoi lavori manoscritti. Tra essi vi sono le Réflexions che Gilles Banderier presenta in questo volume per la prima volta in versione stampata, e nelle quali l'autore difende la figura e l'opera di dom Calmet. Come lui, egli riconosce il carattere di verità delle apparizioni di angeli o anime narrate nella Bibbia, ma non quelle che, a suo giudizio, appartengono alla categoria delle superstizioni, come la credenza nell'esistenza dei vampiri. Il Traité, fa notare Cathelinot, è stato criticato a partire dall'idea secondo la quale nel Secolo dei Lumi non è più giustificabile una fede ingenua ed irrazionale in fantasmi, spiriti maligni, morti viventi, apparizioni di anime o di entità spirituali di altri mondi; ma, argomenta il suo difensore, l'errore compiuto dai detrattori di quel libro, sulla scia di Voltaire, è stato quello di attribuire all'autore le credenze che egli stesso cercava di dimostrare infondate, perfino attribuendole alla sua età avanzata.

4 Le Réflexions non costituiscono una mera apologia del Traité e vanno oltre la semplice difesa del loro autore. Esse sono anche un trattato di teologia che dialoga con Sant'Agostino, del quale il volume include la traduzione francese di una parte del $D e$ cura gerenda pro mortuis (pp. 151-170) che compariva nel Traité historique et dogmatique sur les apparitions, les visions et les révélations particulières (1751) di Lenglet-Dufresnoy. Oltre che di questo testo agostiniano, l'edizione dell'opera di Dom Idelfonse Cathelinot è arricchita anche delle recensioni delle Dissertations di Dom Calmet apparse lo stesso anno della loro pubblicazione nei Mémoires de Trévoux e nel Journal des sçavans. 